\title{
Resenha
}

\section{O ESTADO ISLÂMICO E O SEU "CALIFADO IMAGINÁRIO”}

Katty Cristina Lima Sá ${ }^{149}$

\section{WOOD, Graeme. A Guerra do fim dos tempos: o Estado Islâmico e o mundo que}

ele quer. São Paulo: Cia das Letras, 2017.

O Estado Islâmico (ou ISIS, na sigla em inglês ${ }^{150}$ ) é um dissidente da Al-Qaeda que ganhou notoriedade ao proclamar-se um Califado ${ }^{151} \mathrm{em}$ junho de 2014. Ao realizar este ato, o grupo liderado por Abu Bakr Al-Baghdadi152 (1971-) colocou-se como um Estado Westfaliano governado por uma interpretação radical da sharia - conjunto de leis islâmicas, cujos domínios abrangiam territórios da Síria e do Iraque. A partir disso, inúmeros pesquisadores procuraram investigar as origens, a estrutura e os mecanismos de sedução desta entidade que atraiu simpatizantes de diversas nacionalidades através de mensagens e atos de extrema violência, que incluíram decapitações, sequestros, estupros e escravização de prisioneiros.

Entre aqueles que se dedicaram a analisar o ISIS, está Graeme Wood, professor de Ciência Política da Universidade de Yale e correspondente do periódico norte-

\footnotetext{
149 Mestranda em História Comparada pela Universidade Federal do Rio de Janeiro (PPGHC/UFRJ) e graduada em História pela Universidade Federal de Sergipe (UFS). Integrante do Grupo de Estudos do Tempo Presente (GET/UFS). E-mail: katty@getempo.org / Link para Lattes: http://lattes.cnpq.br/6129885151774194. Orientador: Prof. Dr. Dilton Cândido Santos Maynard.

150 Graeme Wood apontou três nomenclaturas para o Estado Islâmico: Islamic State, Islamic State in Siria and Iraque e, por fim Islamic State in Iraq and Sham, a última, referente a sigla ISIS, é a mais utilizada pela mídia internacional. Ver mais em: WOOD, Graeme. A Guerra do fim dos tempos: o Estado Islâmico e o mundo que ele quer. São Paulo: Cia das Letras, 2017.

${ }^{151}$ Império Islâmico formado durante o século VIII, cem anos após a morte de Maomé, cujos domínios incluíram territórios do Sudeste Asiático, Oriente Médio, Norte da África e Península Ibérica. Sua autoridade máxima, o califa, era considerado o sucessor do Profeta Maomé tanto em sua liderança política quanto religiosa.

152 Nascido em 1971 na cidade de Samarra, Iraque como Ibrahim Awwad Ibrahim al-Badri, Al-Baghdadi ingressou no movimento jihad na década de 1990 através da Irmandade Muçulmana. Após a ocupação americana no Iraque (2003-) tornou-se militante na associação terrorista Jamaat Jaysh Abl al-Sunnah wa-lJamaah e permaneceu encarcerado na prisão de Camp Bucca entre 2004 e 2009. Tornou-se líder do Estado Islâmico por volta de 2011 quando o grupo ainda era associado a Al-Qaeda, mas manteve sua identidade em sigilo até proclamar-se Califa. Ver mais em: COUNTER EXTREMISM PROJECT. Abu Bakr alBaghdadi [verbete]. Disponível em: https://www.counterextremism.com/extremists/abu-bakr-albaghdadi. Acesso em 23 de março de 2018.
} 


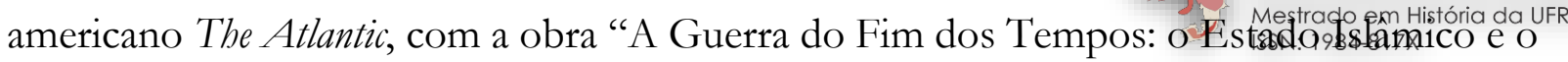
mundo que ele quer”. Lançado pela Companhia das Letras em 2017, o livro é composto por sete capítulos e difere de outros publicados anteriormente por não se propor a relatar o histórico do Estado Islâmico ou analisar o modelo de gestão dos territórios que estiveram sob seu domínio. O objetivo de Wood é identificar a visão dos ativistas deste grupo sobre as ações violentas praticadas na Síria e Iraque e como eles justificavam tais acontecimentos com base nos escritos sagrados islâmicos.

Segundo Wood, o estabelecimento e crescimento do Estado Islâmico não podem ser explicados somente por causas políticas, sociais e econômicas. Deste modo, o caráter religioso é considerado essencial para explicar a ascensão do grupo terrorista na Síria, tendo em vista o conhecimento das escrituras corânicas demonstrado pelos seus líderes e da preocupação constante em acrescentar o aspecto espiritual, sobretudo da salvação da alma, nos materiais de propaganda produzidos por estes extremistas. Deste modo, para investigar a relação entre os atos violentos praticados ISIS com preceitos religiosos maometanos, o autor utilizou relatos e considerações feitas por simpatizantes do Estado Islâmico no Ocidente, especialistas de teologia islâmica, e por adeptos das vertentes quietistas e radicais do salafismo ${ }^{153}$.

Na visão do autor, o ISIS não se fortaleceria tanto e em um período tão curto de tempo, "se já não existissem milhões de pessoas famintas por aquilo que o Estado Islâmico prometia" (WOOD, 2017, p.17). Por isso, o livro se inicia com uma síntese acerca do salafismo, da concepção de jihad ${ }^{154}$ construída por salafistas extremistas como Abdel-

153 Corrente ideológica do Islã em que é pregado o "retorno" ao estilo de vida do Profeta Maomé e das três primeiras gerações de seus primeiros seguidores. A partir do século XX este pensamento se uniu a política e ganhou tônica militante a partir da criação da Irmandade Muçulmana no Egito (1928) e dos escritos de Sayid Qutb (1906-1966). Ver mais em: BRAGA, Ada Viana. A disseminação do Salafismo na Grã-Bretanha. 2009. Dissertação (Mestrado em Ciência Política). Programa de Pós-Graduação em Ciência Política - Universidade Federal do Rio de Janeiro. Rio de Janeiro, 2009.

${ }^{154}$ Esforço para manter-se fiel aos ensinamentos de Alá passados pelo Profeta Maomé. Sua aplicação se refere à atividade individual em cumprir as condutas comportamentais expressas nos textos sagrados, sendo aplicada a ideia de "guerra santa" em alguns momentos da história do Império Islâmico, como quando este sofria algum ataque externo. Os grupos islamitas aplicam o conceito de jihad como guerra santa a partir do fim do século XX tendo como argumento a ideia de que existe um embate político e cultural entre o Ocidente e o Mundo Islâmico. Cf. THACKRAH, Jonh Richard. Jihad [verbete]. In: Dictionary of Terrorism. Nova York: Routledge, 2004, p. 85. 


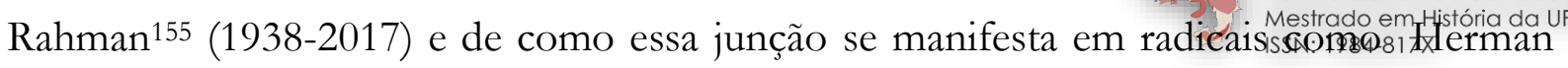
Elashry, com quem Wood conviveu na cidade do Cairo. Através de Elashry, conhecem-se interpretações religiosas que permitem a escravidão e os castigos físicos, bem como algumas técnicas de aliciamento empregadas pelo ISIS que também fazem parte do trabalho do entrevistado, cuja especialidade é converter novos militantes.

Enquanto o primeiro capítulo é dedicado a expor o contexto histórico-social da constituição do grupo, o segundo apresenta o histórico da organização e como agem algumas de suas lideranças. Neste momento, o autor destaca duas figuras: o juiz de práticas religiosas do "Califado", Turki al-Binali, e o autoproclamado califa Abu Bakr Al-Baghdadi, ambas as figuras ressaltadas pelo interesse de confirmar seus conhecimentos da religião e cultura maometana e por empregar simbolismos remetentes ao século VIII. Em seguida, a obra passa a falar para alguns ativistas pró-ISIS, que em capítulos distintos apresentam suas concepções e justificativas para as práticas violentas do "Califado".

Wood entrevistou quatro simpatizantes da organização terrorista conhecidos por divulgar as ideias deste na Internet, mas que nunca estiveram nos territórios controlados pelo ISIS ou tiveram apenas breves passagens por estes. A constatação do autor é de que as idealizações elaboradas por homens são destoantes dos relatos de corrupção, desigualdade, racismo e xenofobia feitos pelos dissidentes do grupo. Isto também exemplifica a afirmação feita ainda no início da obra, da existência de dois Estados Islâmicos: o primeiro é físico com "um território, guerra e economia para administrar" (WOOD, 2017, p. 23) e outro imaginário, visto como um santuário de virtude e igualdade. O último é concebido e difundido pelos admiradores do Califado através daquilo que leram em escritos religiosos islâmicos datados do medievo, mas que é aplicado nas experiências em seus próprios Estados e culturas.

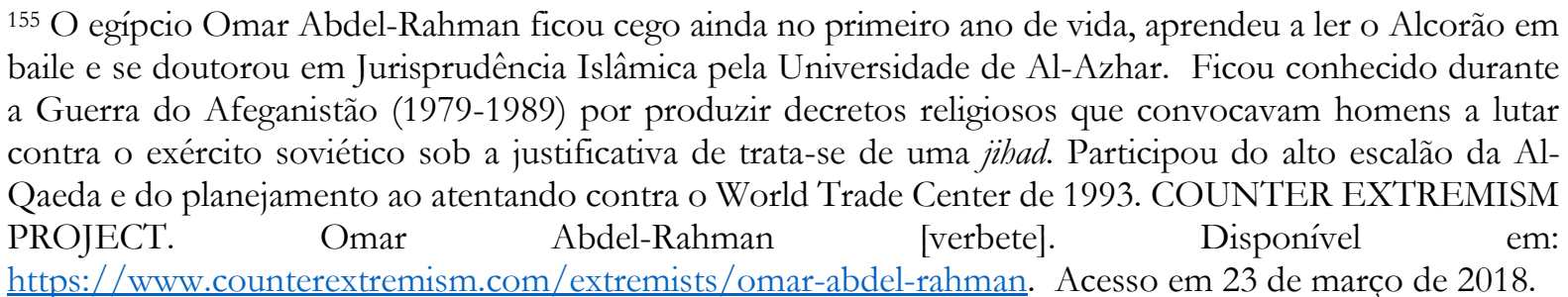




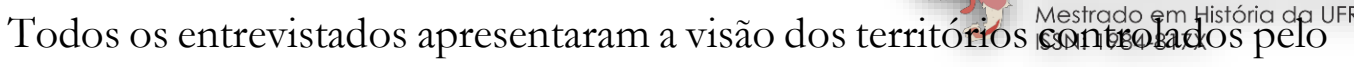

Estado Islâmico como um santuário em que muçulmanos de todas as origens podem viver plenamente sua fé. Ações punitivas como a amputação de membros e a pena de morte não são tidas retrógradas ou como uma afronta aos direitos humanos, mas como a aplicação da sharia feitas por juízes especializados dentro de um sistema legal e imparcial. Sendo assim, segundo Ajun Choudary, simpatizante do ISIS no Reino Unido, "quando é proferido um veredito de culpa e a sentença é a amputação, o Estado Islâmico toma precauções para que a punição não exceda seu intuito" (WOOD, 2017, p. 240). Penas de morte, por sua vez, são dadas como um ato de misericórdia, pois permitem a "purificação" do criminoso e pecador (WOOD, 2017, p. 147).

Outro ponto destacado por Wood na idealização do "Califado" feita por seus entrevistados, são as comparações entre os sistemas de bem-estar social vigentes nos países em que aqueles residiam com aquilo que eles consideravam ações sociais realizadas pelo ISIS dentro seus domínios. O britânico Abu Muhid, por exemplo, afirmou que "o Estado Islâmico pode ter punições medievais para crimes morais, mas seu programa de bem-estar social é bem progressista [...]" (WOOD, 2017, p. 247) e seu modelo de gestão econômica é um modelo a ser seguido pelo Ocidente, visto que se trataria de uma economia livre dos gastos com "vícios morais", como o alcoolismo e a prostituição, e das interferências de banqueiros (WOOD, 2017, p. 277).

Após analisar a visão construída por ativista do Estado Islâmico sobre as práticas deste, o autor procura demonstrar a relação entre esse grupo terrorista e a religião que ele diz defender. Obras como "Life and Death in ISIS", organizada por Zeina Karam (2016), afirmam que o grupo autodenominado Estado Islâmico não deva ser visto como um fenômeno religioso, pois suas concepções não representam o pensamento da comunidade islâmica. Entretanto, Wood rebate esta ideia e afirma que o "Estado islâmico é um fenômeno muçulmano [...]" (WOOD, 2017, p. 279) uma vez que seus estudiosos "não citam Marx, os philosophes, o código de Manu ou o apóstolo Paulo. Citam o Alcorão, o hadith [...]"(WOOD, 2017, p. 280). Para justificar esta concepção, foram entrevistados os especialistas em teologia islâmica Yashir Qadhi, Hanza Yusuf, Imã Abdullah e Yayha Michot, cada um representando uma vertente do Islã. 
As conversas com doutos do Islã apontaram o consenso de qué Oiskistrada em Hijtária.da UFR faz um entendimento próprio dos textos sagrados sem uma segunda instrução, que é dada após o estudo aprofundado dos textos de teólogos islâmicos clássicos. No entanto, esta conclusão não satisfaz Wood que afirma ser necessário rebater a leitura religiosa do Estado Islâmico através da interpretação dos mesmos textos feita por estudiosos do Islã contemporâneos, em uma espécie de "fogo contra fogo" em que são apontados os equívocos da pregação do grupo terrorista. Com tudo isso, o autor que opta por finalizar o capítulo com a questão em aberto, a espera de uma resposta futura.

Por fim, no último capítulo a obra aborda a visão escatológica do Estado Islâmico que, como apontou Wood, tem grande importância para a propaganda e o recrutamento. Tamanha é a importância dos eventos apocalípticos para o grupo, que o primeiro periódico digital produzido por este entre 2014 e 2016 foi intitulado de Dabiq. Este título se refere à cidade homônoma no norte da Síria, onde segundo a tradição corânica acontecerá os primeiros eventos do juízo final.

Segundo Wood, o medo do fim do mundo traz consigo o temor da condenação e a busca pela purificação, que seria possível através de uma vida “sem pecados" regida pela "mão firme" de um Califado. Também cabe ressaltar que a morte não é temida dentro do discurso jihadista, mas ansiada. Isso acontece devido a concepção de "martírio" existente entre terroristas islâmicos, em que os mortos em decorrência da "guerra santa" são agraciados por Alá na vida post mortem. Com isso, tornar-se um “mártir de Alá” tem grande prestígio entre os jihadistas, o que se torna ainda maior quando se trata de um "guerreiro do apocalipse".

Para além dos temas já tratados, o livro de Wood apresenta também os pormenores acerca do Estado Islâmico, como a biografia de um de seus recrutados mais importantes, o americano Yahya Georgelas, e as correntes de pensamento dentro do salafismo que presentes na estrutura da organização terrorista. Além disso, em dados momentos o autor relaciona as divergências do ISIS com a Al-Qaeda, em especial entre aqueles que foram formados dentro do círculo de Osama Bin Laden ${ }^{156}$ (1957-2011) com

\footnotetext{
156 Osama Bin Laden nasceu na Arábia Saudita em 1957 e é o décimo sétimo filho do milionário de origem iêmita Mohammed bin Laden. O contato de Osama com o fundamentalismo islâmico se deu ainda no ensino médio, quando este entrou em contato com os escritos de Sayyid Qutb, porém seu ingresso no
} 
seus ex-tutores.

Com tudo isso, a obra de Graeme Wood transmite de maneira satisfatória a constituição do pensamento do ISIS, como este se utiliza da religião e qual a imagem que este reproduz para seus simpatizantes espalhados pelo mundo. Através do exposto pelo autor, podemos identificar com mais clareza os motivos pelo rápido crescimento em adeptos e simpatizantes que o Estado Islâmico obteve após junho de 2014: a idealização do Califado e a promessa de viver uma vida próxima aquela de seu país de origem nos quesitos de consumo e bem-estar social, com o acréscimo de viver plenamente os ensinamentos de Maomé. Como afirmou o ativista pró-Isis Musa Cercatônio em suas falas para o autor, "como poderia ser retrógrado um grupo onde seus combatentes usam o tênis Nike Air Jordan e o Twitter?" (WOOD, 2017, p. 147).

Ainda que a tese proposta por Wood, quando mal compreendida, possa acarretar na associação do Islã com a violência praticada por grupos jihadistas, “A Guerra do Fim dos Tempos" é uma leitura proveitosa por demonstrar a constituição do Estado Islâmico em suas raízes ideológicas e que a visão este grupo consegue projetar para seus simpatizantes.

\section{Referências bibliográficas}

KARAM, Zeina, ASSOCIETED PRESS (org.). Life and Death in ISIS: How the Islamic State Builds its Caliphate. Miami: Mango Media - AP Editions, 2016.

\footnotetext{
jihadismo ocorreu com o início da Guerra do Afeganistão em 1979. Finalizado o conflito em 1989, o saudita fundou a Al-Qaeda (A Base) com o objetivo de auxiliar e oferecer donativos a milícias islâmicas espalhadas pelo mundo e esta organização já contou com 54 associados e é a responsável pelo maior atentado terrorista já realizado: o 11 de setembro de 2001, que teve cerca três mil vítimas. Bin Laden foi morto por uma tropa especial americana em maio de 2011 na cidade de Abbottabad, Paquistão. Ver mais em: COUNTER EXTREMISM PROJECT . Osama Bin Laden [verbete]. Disponível em:
} https://www.counterextremism.com/extremists/osama-bin-laden. Acesso em 04 de abril de 2017. 